INTERNATIONAL ASTRONOMICAL UNION

SYMPOSIUM No. 186

\title{
GALAXY INTERACTIONS AT LOW AND HIGH REDSHIFT
}

Edited by J. E. BARNES and D. B. SANDERS
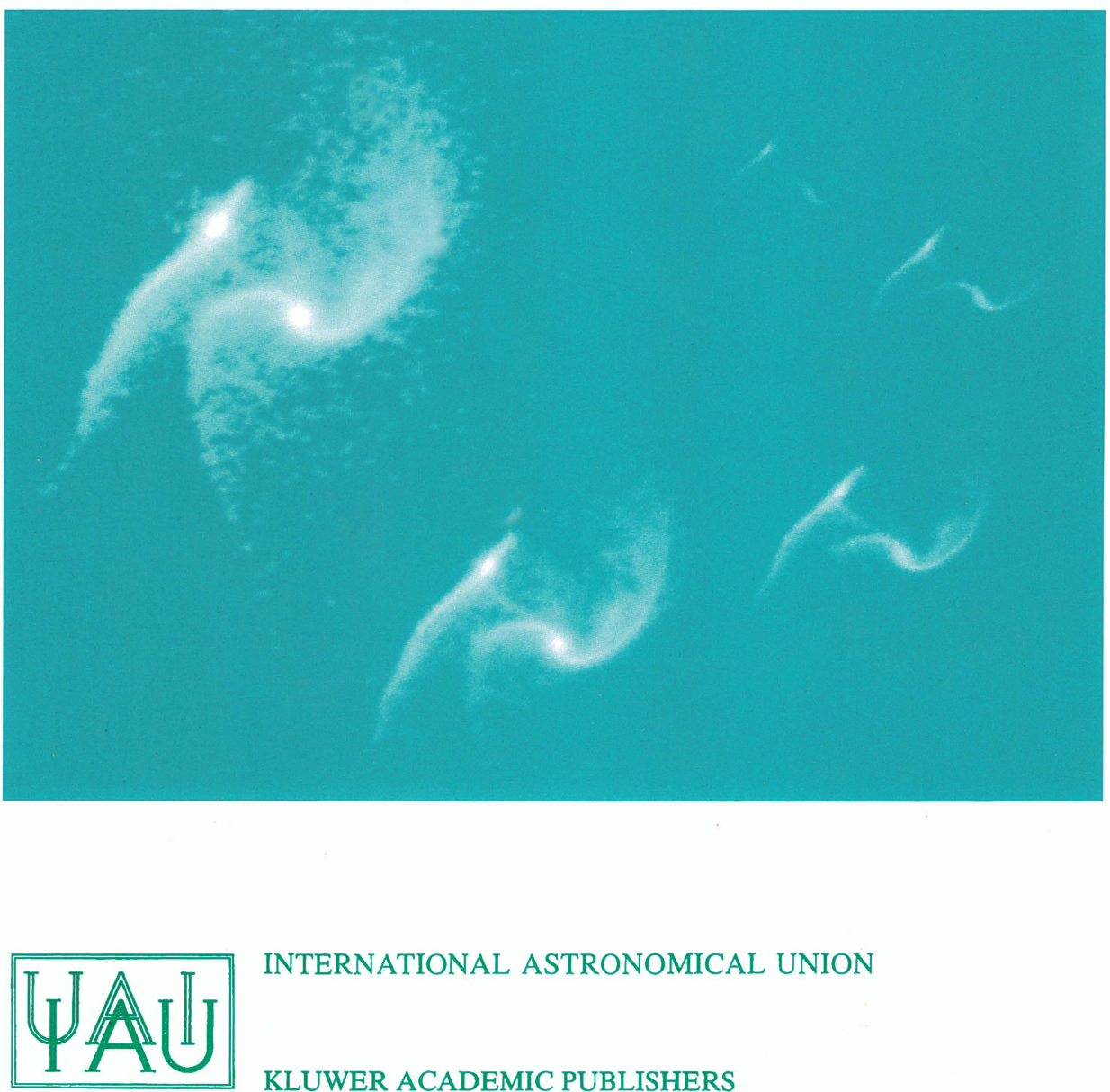

INTERNATIONAL ASTRONOMICAL UNION

KLUWER ACADEMIC PUBLISHERS 


\section{GALAXY INTERACTIONS AT LOW AND HIGH REDSHIFT}

SYMPOSIUM No. 186

The 186th IAU Symposium came at an exciting and perhaps even historic time for extragalactic astronomy. New spacecraft observations plumbed the depths of the Universe out to redshifts of five, while revealing astounding details of nearby galaxies. Early observations with large groundbased telescopes provided extensive coverage of galaxies and AGN at intermediate redshifts. Theoretical ideas on structure formation, together with results from detailed numerical modeling, created a comprehensive framework for modeling the formation of galaxies and the transformation of galaxies by interactions and mergers. All these strands came together at the Symposium as participants glimpsed a developing synthesis highlighting galactic encounters and their role in the history of the Universe. This volume offers professional astronomers. including Ph.D. students, an overview of the rapidly advancing subject of galaxy interactions at low and high redshift. 
GALAXY INTERACTIONS AT LOW AND HIGH REDSHIFT 


\title{
GALAXY INTERACTIONS AT LOW AND HIGH REDSHIFT
}

PROCEEDINGS OF THE 186TH SYMPOSIUM OF THE INTERNATIONAL ASTRONOMICAL UNION, HELD AT KYOTO, JAPAN, 26-30 AUGUST 1997

\author{
EDITED BY
}

J. E. BARNES

and

D. B. SANDERS

Institute for Astronomy,

University of Hawaii,

Honolulu, HI, U.S.A.

KLUWER ACADEMIC PUBLISHERS

DORDRECHT / BOSTON / LONDON

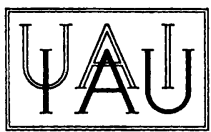


A C.I.P. Catalogue record for this book is available from the Library of Congress.

ISBN 0-7923-5832-5

\title{
Published on behalf of \\ the International Astronomical Union \\ by
}

Kluwer Academic Publishers, P.O. Box 17, 3300 AA Dordrecht, The Netherlands.

Sold and distributed in North, Central and South America by Kluwer Academic Publishers,

101 Philip Drive, Norwell, MA 02061, U.S.A.

In all other countries, sold and distributed by Kluwer Academic Publishers,

P.O. Box 322, 3300 AH Dordrecht, The Netherlands.

Printed on acid-free paper

\author{
All Rights Reserved \\ (C) 1999 International Astronomical Union
}

No part of the material protected by this copyright notice may be reproduced or utilized in any form or by any means, electronic or mechanical, including photocopying, recording or by any information storage and retrieval system, without written permission from the publisher.

Printed in the Netherlands. 


\section{CONTENTS}

PREFACE

xiii

PARTICIPANTS

$\mathrm{xv}$

COLOR PLATES

xix

\section{OVERVIEW}

OVERVIEW: LOW- $z$ OBSERVATIONS

F. Schweizer

A REVIEW OF HIGH-REDSHIFT MERGER OBSERVATIONS

R.G. Abraham,

\section{LOCAL GROUP}

WHAT CAN WE LEARN FROM THE LOCAL GROUP ABOUT THE ROLE OF INTERACTIONS IN GALAXY FORMATION

K.C. Freeman

THE MAGELLANIC STREAM AND THE MAGELLANIC CLOUD SYSTEM

M. Fujimoto, T. Sawa, Y. Kumai

THE NATURE AND FATE OF THE SAGITTARIUS DWARF GALAXY R.A. Ibata

A SEARCH FOR MOVING GROUPS IN THE GALACTIC HALO L.A. Aguilar, R. Hoogerwerf

CONSTRAINTS ON INTERACTIONS AND MERGERS FROM DSPH GALAXIES AND GLOBULAR CLUSTERS

E.K. Grebel

TOTAL MASS AND LUMINOCITY OF STAR FORMING REGIONS IN THE LMC. THE PREDICTED INFRARED FLUXES

V. Missoulis, A. Dapergolas, E. Kontizas, M. Kontizas, S. Oliver

THE MAGELLANIC STREAM REVISITED

T. Murai

ARE THE BULGE C-STARS RELATED TO THE SAGITTARIUS

DWARF GALAXY?

Y.K. Ng

COMPRESSIVE EFFECTS ON THE GALACTIC GLOBULAR

CLUSTERS BY GRAVITATIONAL DISK-SHOCKING

M. Shimada

AN HI SEARCH FOR M81 GROUP DWARF GALAXIES

W. van Driel, R.C. Kraan-Korteweg, B. Binggeli, W.K. Huchtmeier 
THE HIGH-VELOCITY CLOUDS: GALACTIC OR INTERGALACTIC?

H. Van Woerden, U.J. Schwarz, R.F. Peletier, B.P. Wakker,

P.M.W. Kalberla

A NEAR INFRARED SURVEY OF THE LARGE MAGELLANIC CLOUD

T. Wada, M. Ueno, T. Ebisuzaki, Y. Ohno

N-BODY SIMULATIONS OF THE MAGELLANIC SYSTEM INCLUDING GAS DYNAMICS AND STAR FORMATION PROCESS

A.M. Yoszawa, M. Noguchi

\section{TIDAL INTERACTIONS}

TIDAL DWARF GALAXIES

P.-A. Duc, I.F. Mirabel

GALAXY INTERACTIONS: THE HI SIGNATURE

R. Sancisi

TIDAL INTERACTIONS IN M81 GROUP

M.S. Yun

EXTENDED GAS IN INTERACTING SYSTEMS

F. Combes

COLLISIONAL RING GALAXIES

P.N. Appleton

NUMERICAL SIMULATIONS OF M51

M. Antonioletti, A.H. Nelson

105

GALAXY INTERACTIONS IN THE LOCAL VOLUME

I.D. Karachentsev, D.I. Makarov

109

LOPSIDED GALAXIES AND THE SATELLITE ACCRETION RATE

D. Zaritsky, H.-W. Rix

117

"E+A" GALAXIES: ENVIRONMENT AND EVOLUTION

A.I. Zabludoff

RADIO CONTINUUM OBSERVATIONS OF NGC 1961: INTERACTION WITH THE INTERGALACTIC MEDIUM OR THE REMNANT OF A MERGER?

U. Lisenfeld, P. Alexander, G. Pooley

132

DYNAMICAL PROPERTIES OF TIDALLY-INDUCED GALACTIC

BARS

T. Miwa, M. Noguchi

133

STAR FORMATION IN COLLISIONS BETWEEN TWO GAS-RICH

DISK GALAXIES

C. Struck

134

TOWARDS AN INTERACTION MODEL OF M81, M82 AND NGC 3077

R.C. Thomson, S. Laine, A. Turnbull

135

An HI LIN SURVEY OF POLAR RING GALAXIES

W. van Driel, M. Arnaboldi, F. Combes, L.S. Sparke

136

\section{MERGERS \& REMNANTS}

DYNAMICS OF MERGERS \& REMNANTS

J.E. Barnes

THE STRUCTURE OF MERGER REMNANTS OF COMPACT

GROUPS OF GALAXIES: SOME PRELIMINARY RESULTS

E. Athanassoula, Ch.L. Vozikis

COUNTERROTATION IN GALAXIES

F. Bertola, E.M. Corsini 
MAKING SPIRALS WITH COUNTER-ROTATING DISKS

D. Pfenniger

157

STELLAR COUNTER-ROTATION ALONG THE HUBBLE SEQUENCE: A PROBE FOR GALAXY FORMATION

SCENARIOS

F. Prada, C.M. Gutiérrez

161

SHELLS, RIPPLES AND TAILS

D. Carter

165

GLOBULAR CLUSTER SYSTEMS OF ELLIPTICAL GALAXIES

S.E. Zepf, K.M. Ashman

173

GLOBULAR CLUSTERS IN ELLIPTICAL GALAXIES: CONSTRAINTS ON MERGERS

D.A. Forbes

181

FUNDAMENTAL PLANE AND MERGER SCENARIO

K. Bekki

185

MASS DISTRIBUTION OF THE E0 GALAXY NGC 6703 FROM

ABSORPTION LINE PROFILE KINEMATICS

O.E. Gerhard, G. Jeske, R.P. Saglia, R. Bender

189

SHELL FORMATION IN NGC474

A.J. Turnbull, D. Carter, T.J. Bridges, R.C. Thomson

191

FORMATION OF BOXY/PEANUT-SHAPED BULGES IN SPIRAL

GALAXIES: ACCRETION OR BAR INSTABILITY?

M. Bureau, K.C. Freeman

193

THE CHARACTER OF EMBEDDED RINGS

T.K. Chatterjee

194

TRENDS IN GALAXY FORMATION AND EVOLUTION IN THE CONTEXT OF THE VIRIAL AND FUNDAMENTAL PLANES

T.K. Chatterjee, V.B. Magalinsky

195

MASS STRUCTURE OF Sa SPIRALS: NGC 2179 \& NGC 2775

E.M. Corsini, M. Sarzi, P. Cinzano, F. Bertola, A. Pizzella, M. Persic, P. Salucci

196

MULTIMODAL COLOR DISTRIBUTIONS IN THE GLOBULAR

CLUSTER SYSTEMS OF GIANT ELLIPTICAL GALAXIES

D. Geisler, M.G. Lee

197

THE GLOBULAR CLUSTER SYSTEM OF NGC 1399

P. Goudfrooij, M.V. Alonso, D. Minniti

198

THE NATURE OF THE DUSTY IONIZED GAS IN NGC 5846 (AND

OTHER ELLIPTICAL GALAXIES (?))

P. Goudfrooij, G. Trinchieri

199

THE ORIGIN OF HIGH SPECIFIC FREQUENCY GLOBULAR

CLUSTER SYSTEMS

M.G. Lee, D. Geisler

200

ANGULAR MOMENTUM TRANSFER DUE TO GALACTIC WINDS AND COOLING FLOWS

V. Missoulis

201

STELLAR POPULATIONS IN HIGH- $z$ GALAXY MERGERS

Y. Shioya, K. Bekki

202

ORTHOGONAL GASEOUS DISKS IN THE E5 GALAXY IC 4889

J.C. Vega Beltrán, E.M. Corsini, F. Bertola, A. Pizzella

5. STARBURSTS

GASDYNAMICS AND STARBURSTS IN INTERACTING GALAXIES

J.C. Mihos 
FUELING NUCLEAR STARBURSTS

J.P.E. Gerritsen, V. Icke

MOLECULAR GAS AND STAR FORMATION IN INTERACTING AND ISOLATED GALAXIES

J.S. Young

LUMINOUS IR GALAXIES IN A MERGER SEQUENCE: BIMA CO IMAGING

Y. Gao, R.A. Gruendl, C.-Y. Hwang, K.Y. Lo

DRAMATIC CHANGES IN MOLECULAR CLOUD PROPERTIES

ACROSS THE ARP 299 MERGER

S. Aalto, S.J.E. Radford, N.Z. Scoville, A.I. Sargent

231

STARBURSTS TRIGGERED BY CLOUD COMPRESSION IN

INTERACTING GALAXIES

C.J. Jog

THE STELLAR INITIAL MASS FUNCTION IN STARBURST

GALAXIES

C. Leitherer

THE EVOLUTION OF YOUNG STAR CLUSTERS IN MERGING

GALAXIES

B.C. Whitmore

251

BRIGHT STAR CLUSTERS IN THE ANTENNAE ANALYSED WITH EVOLUTIONARY SYNTHESIS

U. Fritze-v. Alvensleben, O. Kurth

261

GAS AND DUST IN ULTRALUMINOUS GALACTIC NUCLEI

N.Z. Scoville, M.S. Yun

PROTO-GLOBULAR CLUSTER CANDIDATES IN NGC 1275

J.P. Brodie

235

243

BSERVATIONS OF LUMINOUS IR GALAXY MERGERS

Y. Gao, P.M. Solomon

STAR-FORMING ACTIVITY IN ARP-MADORE GALAXIES

A. M. Hopkins, L. E. Cram

265

273

275

277

GAS CONTENT OF MARKARIAN STARBURST GALAXIES

R. Kandalyan

279

OCULAR GALAXIES: NGC 2535 AND ITS STARBURST COMPANION NGC 2536

E. Brinks, M. Kaufman, D.M. Elmegreen, M. Thomasson, B.G. Elmegreen, C. Struck, M. Klarić

LUMINOUS INFRARED GALAXIES IN A MERGING SEQUENCE: ISO OBSERVATIONS

C.-Y. Hwang, K.Y. Lo, Y. Gao, R.A. Gruendl, N.-Y. Lu

FORMATION OF PLUMES IN THE HEAD-ON COLLISIONS OF

GALAXIES

V. Korchagin, T. Tsuchiya, K. Wada

283

SINGLE STELLAR POPULATIONS

O.M. Kurth, U. Fritze-v. Alvensleben, K.J. Fricke

284

NEW MODELS FOR MASSIVE STAR POPULATIONS IN YOUNG

STARBURSTS

D. Schaerer, W.D. Vacca

285

NIR LINE OBSERVATIONS OF STARBURST GALAXIES

H. Sugai, M.A. Malkan, M.J. Ward, R.I. Davies, I.S. Mclean

286

ASCA OBSERVATIONS OF LUMINOUS INFRARED STARBURST

GALAXIES

H. Watarai, K. Misaki, Y. Terashima, T. Nakagawa 


\section{NUCLEAR ACTIVITY}

ULTRALUMINOUS INFRARED GALAXIES

D.B. Sanders, J.A. Surace, C.M. Ishida

SPECTROSCOPY OF LUMINOUS INFRARED GALAXIES

S. Veilleux

THE NUCLEAR INTERSTELLAR MEDIUM OF ULTRALUMINOUS

INFRARED GALAXIES

P.P. van der Werf

TRIGGERED STARBURSTS IN GALAXY MERGERS

Y. Taniguchi, Y. Shioya, T. Murayama, K. Wada

INTERACTIONS, MERGERS, AND QSO ACTIVITY
A. Stockton

311

RADIO SOURCE SURVEYS: MERGERS AT HIGH REDSHIFTS?

P.J. McCarthy

UNIFIED SCHEME FOR SEYFERTS OR THE INFLUENCE OF INTERACTIONS?

D. Dultzin-Hacyan, I.F. Guridi, Y. Krongold, P. Marziani

RELICS OF NUCLEAR ACTIVITY: DO ALL GALAXIES HAVE MASSIVE BLACK HOLES?

R.P. van der Marel

ASCA OBSERVATIONS OF LUMINOUS INFRARED GALAXIES

T. Nakagawa, T. Kii, R. Fujimoto, T. Miyazaki, H. Inoue,

Y. Ogasaka, K. Arnaud, R. Kawabe

CFHT ADAPTIVE OPTICS IMAGING OF ACTIVE GALAXIES

J.B. Hutchings

DYNAMICAL EXPLORATIONS OF NUCLEAR STRUCTURES IN

BARRED GALAXIES

J. Anosova, G.F. Benedict

THE FATE OF ULTRALUMINOUS MERGERS

A.C. Baker, D.L. Clements

THE HOST GALAXIES OF IR LUMINOUS QUASARS

D.L. Clements, A.C. Baker, C.J. Lidman

THE NATURE OF ULTRALUMINOUS IRAS GALAXIES

D.L. Clements, W.J. Sutherland, R.G. McMahon

THE INTERACTING SEYFERT 2 GALAXY UGC 3995A

D. Dultzin-Hacyan, P. Marziani, M. D' Onofrio

TESTING THE MERGER HYPOTHESIS OF POWERFUL RADIO

GALAXIES

A.S. Evans, D.B. Sanders, J.M. Mazzarella

NEAR INFRARED SPECTROSCOPY AND THE SEARCH FOR CO EMISSION IN 3 EXTREMELY LUMINOUS IRAS SOURCES

A.S. Evans, D.B. Sanders, R.M. Cutri, S.J.E. Radford,

P.M. Solomon, D. Downes, C. Kramer

SEYFERT GALAXIES AND THEIR ENVIRONMENT

P. Focardi, B. Kelm, G.G.C. Palumbo

RADIATIVE AVALANCHE DRIVEN BY SPHERICAL STARBURSTS

J. Fukue, M. Umemura, S. Mineshige

THE INTERPLAY BETWEEN THE NUCLEAR BARS, CENTRAL

STARBURST, AND REMARKABLE OUTFLOW IN NGC 2782

S. Jogee, J.D.P. Kenney, B.J. Smith

MERGING GALAXIES WITH ACTIVE NUCLEI

W. Kollatschny 
THE DETECTION OF A LARGE, POWERFUL FR I RADIO GALAXY IN A SPIRAL HOST

M.J. Ledlow, F.N. Owen, W.C. Keel

X-RAY STUDY OF ULTRALUMINOUS INFRARED GALAXIES:

ASCA RESULTS OF IRAS20551-4250 AND IRAS23128-5919

K. Misaki, Y. Terashima, H. Watarai, H. Kunieda, K. Iwasawa,

Y. Taniguchi

NEAR-INFRARED OBSERVATIONS OF A TYPE-2 QSO AT $z=0.9$

K. Nakanishi, M. Akiyama, K. Ohta, T. Yamada

CO OBSERVATIONS OF HIGH- $z$ OBJECTS

K. Ohta, K. Nakanishi, M. Akiyama, T.T. Takeuchi, T. Yamada, Y. Shioya, K. Kohno, R. Kawabe, N. Kuno, N. Nakai

HIGH SPATIAL RESOLUTION NEAR-IR TIP/TILT IMAGING OF "WARM" ULTRALUMINOUS INFRARED GALAXIES

J.A. Surace, D.B. Sanders

EVOLUTION OF VERY LUMINOUS INFRARED GALAXIES

H. Wu, Z.L. Zou, X.Y. Xia, Z.G. Deng

ASCA OBSERVATIONS OF THE TYPE-2 QUASAR RXJ13434+0001 AT $z=2.35$

T. Yamada, Y. Ueda, T. Takahashi, K. Ohta, M. Cappi, C. Ohtani, Y. Ishisaki

\section{GROUPS \& CLUSTERS}

COMPACT GROUPS OF GALAXIES

P. Hickson

VLA OBSERVATIONS OF NEUTRAL HYDROGEN IN COMPACT GROUPS

B.A. Williams, J.H. Van Gorkom, M. Yun, L. Verdes-Montenegro

RADIO DIAGNOSTICS OF GALAXY INTERACTIONS

T.K. Menon

ENVIRONMENTAL EXTREMISTS IN THE VIRGO CLUSTER

J. Kenney, R. Koopmann

GALAXY HARASSMENT-INTERACTIONS FOR THE 90s

G. Lake, B. Moore

393

THE X-RAY PROPERTIES OF NEARBY ABELL CLUSTERS FROM THE ROSAT ALL-SKY-SURVEY

M.J. Ledlow, W. Voges, F.N. Owen, J.O. Burns

401

INVESTIGATIONS OF ENVIRONMENTAL EFFECTS IN CLUSTERS OF GALAXIES USING N-BODY SIMULATIONS

N.A. Popescu, M.D. Suran

403

COLOUR GRADIENTS IN CLUSTERS OF GALAXIES

M.D. Suran, N.A. Popescu

405

THE K-BAND HUBBLE DIAGRAM FOR THE BRIGHTEST CLUSTER

GALAXIES: A TEST OF GALAXY FORMATION MODELS

A. Aragón-Salamanca, C.M. Baugh, G. Kauffmann

407

DISTRIBUTION OF STOCHASTIC FORCES IN GRATATIONALLY

CLUSTERED SYSTEM OF GALAXIES

E. Ardi, S. Inagaki

408

ENVIRONMENTAL EFFECTS

D.F. de Mello, T. Wiklind, M. Maia

GALAXY ORIENTATION IN SOME ABELL CLUSTERS

W. Godłowski, F. Baier 
ENVIRONMENTAL INFLUENCE ON STAR FORMATION OF

GALAXIES IN THE LAS CAMPANAS REDSHIFT SURVEY

Y. Hashimoto, A. Oemler

A NEW AUTOMATED SAMPLE OF COMPACT GROUPS OF GALAXIES

A. Iovino, E. Tassi, C. Mendes de Oliveira, P. Hickson, H. MacGillivray

LARGE SCALE GRADIENT IN THE VELOCITY FIELD OF COMA CLUSTER AND A STUDY OF THE SPIN ORIENTATION OF GALAXIES IN THE VIRGO CLUSTER

M. Iye, T. Ozawa

MOLECULAR GAS IN HICKSON COMPACT GROUPS

S. Leon, F. Combes, T.K. Menon

A K-BAND LUMINOSITY FUNCTION OF HICKSON COMPACT GROUPS OF GALAXIES

S. Nishiura, T. Murayama, Y. Taniguchi, Y. Sato, D.B. Sanders

EFFICIENT STAR-FORMATION IN THE TIDAL ARMS OF

THE STEPHAN'S QUINTET GROUP OF GALAXIES

Y. Ohyama, S. Nishiura, T. Murayama, Y. Taniguchi

416

MEASURING SUBCLUSTERS IN GALAXY CLUSTERS

Z.Y. Shao

NUCLEAR ACTIVITY IN THE HICKSON COMPACT GROUPS OF GALAXIES

M. Shimada, S. Nishiura, Y. Ohyama, T. Murayama, Y. Taniguchi

EVOLUTION OF SUBSYSTEMS DURING COLLAPSE OF A CLUSTER

T. Tsuchiya

ROSAT OBSERVATIONS OF CLUSTERS CL0500-24 \& CL0939+4713

J. Wambsganss, S. Schindler

A MULTI-MERGING GALAXY MRK 273 WITH HOT EXTENDED

GASEOUS HALO AND AN EXTENDED SOFT X-RAY

COMPANION

X.Y. Xia, Z.G. Deng, H. Wu, T. Boller

\section{DEEP FIELDS \& EVOLUTION}

THE HIGH REDSHIFT POPULATION OF FIELD GALAXIES

D.C. Koo

DYNAMICS AND INTERACTIONS OF HIGH-REDSHIFT GALAXIES

M. Noguchi

STRONG GRAVITATIONAL LENSING ON THE HUBBLE DEEP FIELD

R. D. Blandford

MEASURING THE EVOLUTION OF THE MASS-TO-LIGHT RATIO FROM $z=0$ TO $z=0.6$ FROM THE FUNDAMENTAL PLANE M. Franx, P. van Dokkum, D. Kelson, G. Illingworth, D. Fabricant

POPULATION SYNTHESIS IN A UNIVERSE OF INTERACTING

GALAXIES

G. Bruzual

EMISSION LINE GALAXIES AT $1<z<1.5$

K. Glazebrook, R.G. Abraham, C.A. Blake

DISTANT RADIO GALAXIES: PROBES OF THE FORMATION OF MASSIVE GALAXIES

H. Röttgering, P. Best, L. Pentericci, G. Miley 
LOW-IONIZATION BALQSOS: WARM ULTRALUMINOUS GALAXIES AT HIGH REDSHIFTS

E. Egami

A DEEP, LARGE-AREA K-BAND SURVEY FOR HIGHLY REDSHIFTED H $\alpha$ EMISSION

P.P. van der Werf

479

ARE PRESSURE-CONFINED CLOUDS IN GALACTIC HALOS POSSIBLE FOR A MODEL OF LYMAN ALPHA CLOUDS?

K. Miyahata, S. Ikeuchi

481

METAL ENRICHMENT OF LY $\alpha$ CLOUDS AND INTERGALACTIC MEDIUM

I. Murakami, K. Yamashita

482

EVOLUTION OF DWARF GALAXIES IN HIGH PRESSURE ENVIRONMENTS

I. Murakami, A. Babul

THE EFFECTS OF SPATIAL CORRELATIONS ON MERGER TREES OF DARK MATTER HALOS

M. Nagashima, N. Gouda

ON THE ANGULAR CORRELATION FUNCTIONS OF THE HUBBLE DEEP FIELD

B.F. Roukema

485

FAR-IR GALAXY COUNTS EXPECTED IN THE IRIS SURVEY

T.T. Takeuchi, H. Hirashita, T. G. Hattori, K. Ohta, H. Shibai

486

CLUSTERING OF RED GALAXIES NEAR A RADIO-LOUD QUASAR AT $z=1.086$

I. Tanaka, T. Yamada, A. Aragón-Salamanca, T. Kodama, K. Ohta, N. Arimoto

A SEARCH FOR EXTENDED OBJECTS WITH VARIABLE NUCLEI

D. Trèvese, M.A. Bershady, R.G. Kron

GALAXY MORPHOLOGY, INITIAL CONDITIONS AND THE

HUBBLE SEQUENCE

P.R. Williams, A.H. Nelson

489

THE FORMATION OF GALAXY DISKS AND BULGES

P.R. Williams, A.H. Nelson

490

HUBBLE SEQUENCE AS A TEMPORAL EVOLUTION SEQUENCE

$\mathrm{X}$. Zhang

491

\section{PERSPECTIVES}

NGST: SEEING THE FIRST STARS AND GALAXIES FORM

H.S. Stockman, J. Mather

493

AUTHOR INDEX

501

SUBJECT INDEX

505

OBJECT INDEX 